\title{
RUSSIAN INDUSTRY IN JUNE 2016 \\ (base on data obtained from business surveys conducted by Gaidar Institute) ${ }^{1}$
}

First June data about Russian industry demonstrate a more positive dynamics of demand and output than data obtained during previous "crisis" months. However, enterprises in their plans and projections are not ready so far to weather the slow rolling crisis, which they have managed to adapt to according to their own assessments.

\section{Demand for industrial products}

According to assessments made by enterprises, the balance (rate) of demand on industrial products reached in June untypically for this month solid values. The initial balance turned out to be a fiveyear monthly peak and following seasonal adjustment proved to be a three-year record high (Fig. 1). Moreover, the latest value of this indicator is not an accidental "upsurge" against the backdrop values posted during previous months. In MarchMay, the balance of changes in demand demonstrated definitely better values than a year before and were matching with values of similar and then non-crisis

CHANGES IN SEASONALLY ADJUSTED EFFECTIVE DEMAND (BALANCE $=\%$ GROWTH-\%REDUCTION)

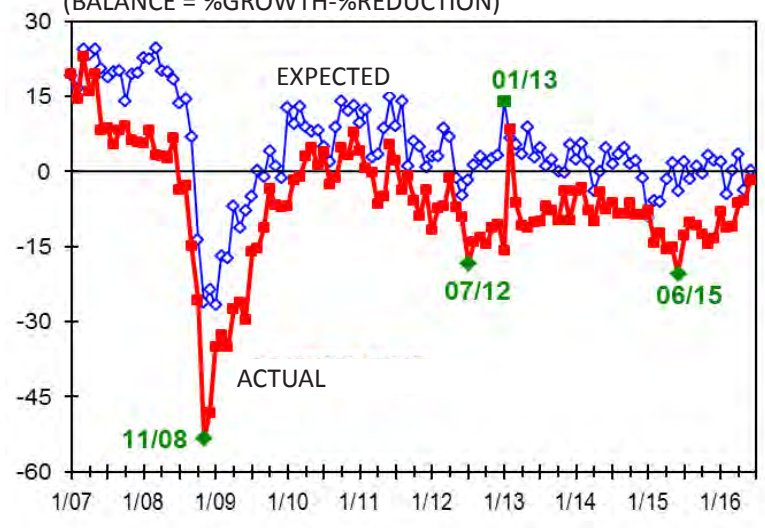

Fig. 1 months of 2014.

In spite of the improvement of indicators of sales shifts, satisfaction with their sales volumes achieved in June fell from 54 to $51 \%$. The best result this indicator demonstrated in April 2016 amounted to 55\%. In August 2016, satisfaction with demand hit $60 \%$.

Seasonally adjusted forecasts of demand shifts remain around zero. Therefore, the industry having come to terms with panic characteristic of the turn of 2015 consistently remains in the state of stagnation regarding demand expectations.

\section{Stock of finished products}

The estimated stock of finished products, according to businesses, remain predominantly in normal volumes (Fig. 2). The proportion of "normal" since the onset of the "crisis of 2014-2016 does not decrease below 70\% on average during quarter, and among remaining $27-30 \%$ register moderate and by far not crisis predominance of "above normal" responses. If to believe the official statistics regarding stock of finished products, according to which the

1 Business surveys of managers of industrial enterprises have been conducted by the Gaidar Institute using a European harmonized method in monthly cycles since September 1992, covering the entire territory of the Russian Federation. The panel size is about 1,100 enterprises employing over $15 \%$ of industrial employees. The panel is shifted towards large enterprises for each of the segregated sub-industries. The ratio of returned questionnaires is $65-70 \%$. 
physical volumes were decreasing, then Russian industry is implementing a highly rational policy of stock management by purposefully and orderly reducing their volume in the context of highly unlikely upsurge of demand on their products.

\section{Stock of raw and other materials}

Similar situation is observed regarding stock of raw and other materials. The "crisis" of 2014-2016 has not entailed any crisis shifts in the business's estimations of their volumes (Fig. 3). The proportion of "normal" responses in late 2014 - early 2015 demonstrated by far from crisis stability. During recent four quarters, the indicator remains in the range of (77-80\%), which enterprises rarely managed to ensure during previous non-crisis years. In 20142016, the balance of remaining responses ("above normal" - "below normal") stays in the range of $-13 \ldots-7$ points, which by no means reflects crisis values of 2009 indicator, when the balance fell to -26 points or its prior default values of $-70 \ldots-60$ points. Consequently, the industry never faced problems regarding backing output with raw and other materials in the face of protracting "crisis."

This conclusion is supported by another indicator - downward pressure on the output by the shortage of raw and other materials. According to enterprises' estimations,

ENTERPRISES' ESTIMATS OF STOCKS OF FINISHED PRODUCTS 1992-2016, BALANCE - \%ABOVE NORMAL — \%BELOW NORMAL)

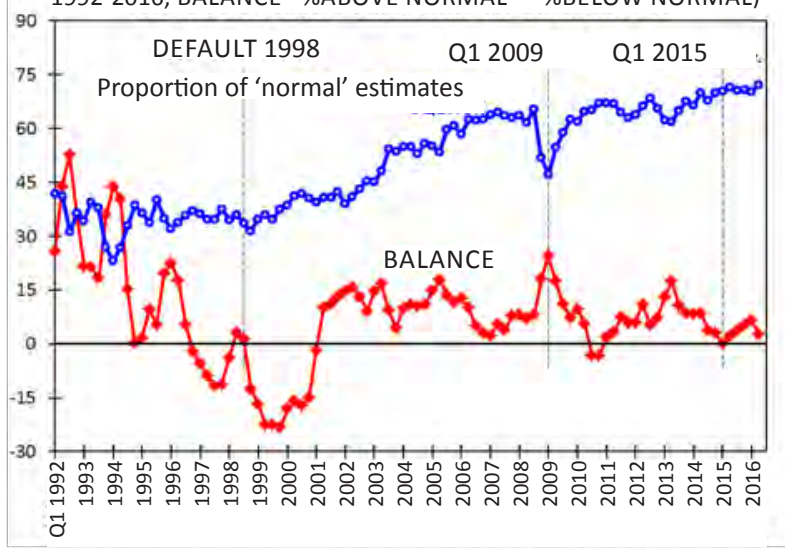

Fig. 2

ENTERPRISES' ESTIMATS OF STOCKS OF FINISHED PRODUCTS

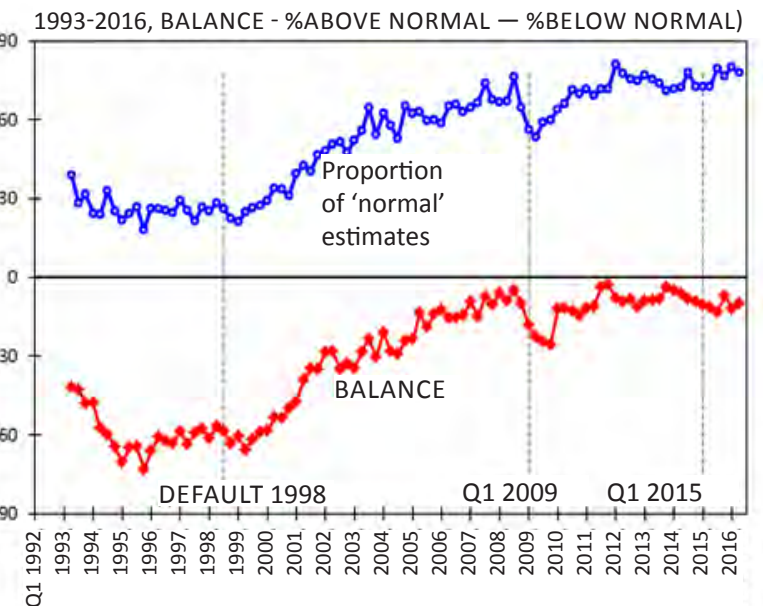

Fig. 3 this factor during recent and "crisis" years remains at the all-time (1995-2016) minimums of its negative affect on the industrial growth. Barely 8-9\% of enterprises report in 2012-2016 the shortage of raw and other materials as a constraint to their output growth.

\section{Output}

Data on output as the data on demand also look very positive at least in the eyes of entrepreneurs. The initial (prior to seasonal adjustment) balance of the industrial production volumes also demonstrates the best result compared to the data of June 2012-2015. Seasonal adjustment of survey data demonstrates the fact that Russian industry achieved in June 2016 the best result regarding output dynamics since August 2014, i.e. since the onset of the current slow rolling crisis.

However, the progressively dynamic output so far does not strike continuation in the industrial plans of enterprises. In June, initial balance of these plans shed 11 points, and following seasonal adjustment -2 , but as a result dropped to the minimum of 2012-2016 (Fig. 4). It seems, that the industry does not see sufficient reasons for commencing statistically noticeable by the 
authorities output growth, first of all owing to insufficient demand volumes, and second, due to unclear prospects of Russian economy rebound from protracted crisis, which commenced in 2014.

\section{Business investment plans}

In June, Russian industry had another shot at terminating the investment pause. Business investment plans register downward trend towards zero, which means increased plans for investment growth and reduced plans for the contraction. However, there are as before more the latter, which leaves the investment plans balance "in the negative" for 21 months in a row - since October 2014. March 2016 result ( -2 points) so far remains the best investment sentiments in Russian industry in the course of the current investment crisis (Fig. 5). In this case, we use the word crisis without quotation marks because the fall of the investment plans in industry in September 2014 - February 2015 reached 43 points (balanced crashed to -36 points) and can rightly be considered as a crisis. Although in 2009, the indicator fell to -59 points, wherein the current monitoring of these plans was commenced in May 2009. However, in January 2010 the balance registered positive.

On the other hand, real investment volumes (not plans!) of Q2 2016 satisfy the majority of Russian industrial enterprises. June estimate of the last quarter has demonstrated that satisfaction with investment went up over three months from 44 to 56\% (Fig. 5) and hit the best result since September 2014.

\section{Investment incentives}

Private investment revival now depends mainly on clarity and predictability of macroeconomic situation. This factor has become an absolute leader according to businesses, although a year ago it was only a part of leaders group consisting of four factors (Fig. 6). Twelve months now elapsed, three factors reduced (two of them by 15 p.p.) its significance for investment decisions in Russian industry and shifted to the second and third places. "Clarity and predictability of macroeconomic situation," on the contrary have increased their significance by 9 p.p. to $61 \%$. To note, this factor turned out to be the only one which significance for the industry has been constantly growing since January 2014.

Equipment prices factor takes the second place. Businesses netting from the sale of their products on domestic and closer to it markets, ruble's devaluation in the context of a lack of domestic production of many types of equipment means a reduction of ability to purchase foreign-made equipment. 
Now (in the wake of somewhat strengthening of the ruble exchange rate and growth of financial savings by industry) this factor has shed 5 p.p., but remains important for half of Russian industry.

The urgency to reduce the interest rate on credits shed throughout the year 15 p.p. b shifted to the third place with $36 \%$ of responses. In view of this, the cost of money factor for industry has now returned to the pre-crisis level of significance.

\section{Loans to industry}

In June, the minimum rate offered by the banks to Russian industry contracted by another 2 p.p. and reduced to $15.5 \%$ annualized in rubles. Therefore, since August 2015 (when the Bank of Russia maintained the key rate at $11.0 \%$ through June decision about its decrease) our indicator has shed barely 1.1 p.p. To note, in the inter-crisis period the minimum rate declined below $12.0 \%$ on average for industry, and for large metallurgical enterprises - to $9.0 \%$. At present, banks offer $14.8 \%$ annual interest rate for this category of borrowers. The light industry traditionally gets the highest rate (in Q2 2016, it hit $16.5 \%$ on average across sector).

On the whole, just over half of Russian industry have acceptable credit availability in Q2 2016 (according to its own and direct

INCENTIVES OF THE INVESTMENT ACTIVITY OF RUSSIAN INDUSTRIAL ENTERPRISES 2014-2016,\%

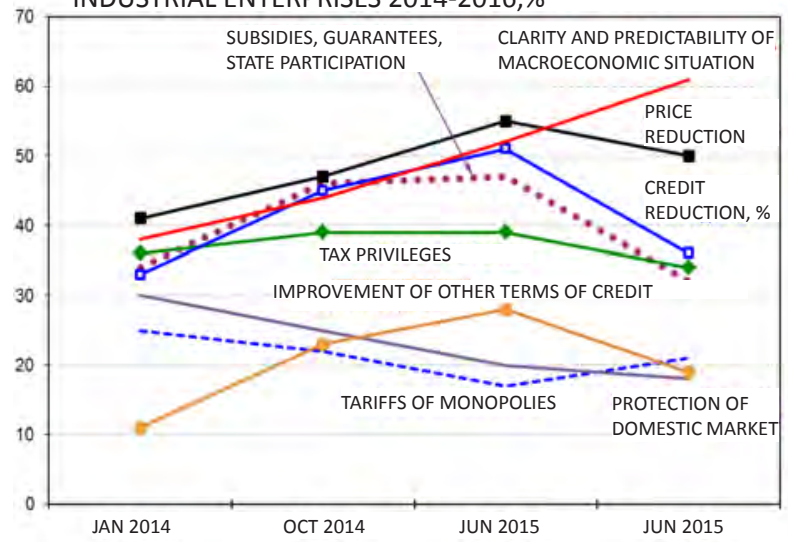

Fig. 6

THE SHARE OF ENTERPRISES WITH ACCESSIBLE CREDIT AVAILABILITY 2000-2016, AVERAGE OF QUARTER, \%

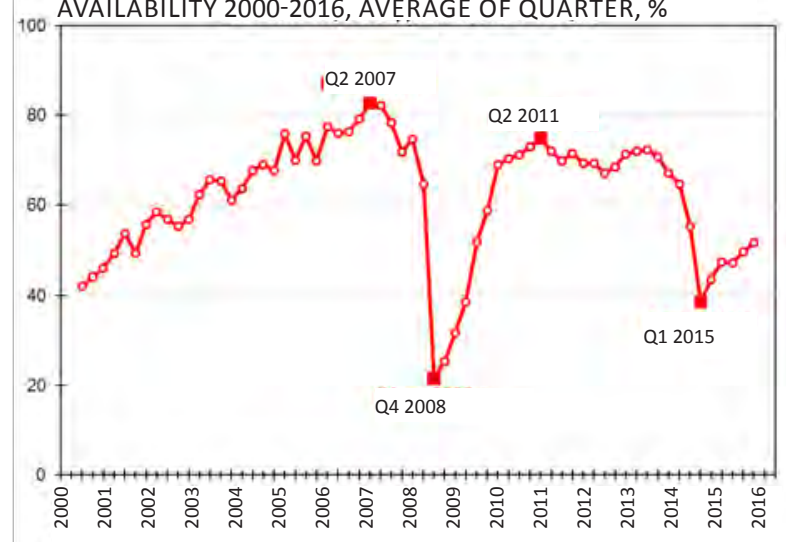

Fig. 7 assessments!) (Fig. 7). At the best of intercrisis times, this indicator hit up to $75 \%$, and prior to crisis of 2008-2009, it reached $82 \%$.

Enterprises' estimates of credit availability demonstrate that during current crisis 2014-2016 the indicator decreased "barely" to 38\%, meanwhile at the peak (bottom) of the previous crisis 2008-2009, it reached $21 \%$ according to average quarterly data. In other words, this crisis is inferior to the previous one (nearly twice) along this indicator. The indicator's drop magnitude during the peak quarter of each crisis complements the picture of the slow-rolling credit crisis in industry. If in 2008-2009, the minimum was reached as a result of reduction of credit availability from 64\% (Q3 2008) to 21\% (Q4 2008), then during the current crisis the drop was from 55\% (Q4 2014) to 38\% (Q1 2015).

However, during the previous crisis lending terms and conditions were recovering more dynamically than at present. Then, industry and banks took six quarters following the crisis minimum in order to return the relations between the creditors and borrowers to the pre-crisis level. Now (in the course of the current crisis) five quarters passed and the indicator has recovered merely 14 p.p. of the drop. It is hardly surprising that in Q3 2016, businesses will significantly change their estimates regarding credit availability even following the June decrease of the key rate by the Bank of Russia. 